\title{
Os efeitos das emoções no ensino-aprendizagem de inglês e na formação do futuro professor: uma análise com base no feedback corretivo oral
}

\author{
Tarsila Rubin Battistella \\ Instituto Federal do Rio Grande do Sul \\ tarsilarb@hotmail.com
}

\begin{abstract}
Resumo
Este trabalho apresenta uma análise das emoções em um ambiente presencial de ensino, bem como a relação que pode ser estabelecida entre o feedback corretivo oral e as emoções, por meio da triangulação de dados, e que podem influenciar na formação do futuro professor e no ensino-aprendizagem de línguas. Procuramos ainda identificar as reações dos aprendizes ao feedback corretivo oral recebido pela professora e/ou pelo colega no contexto formal de ensino-aprendizagem de inglês. Os resultados demonstram que os aprendizes apresentam sentimentos distintos quanto à correção, estando relacionados diretamente às crenças destes e que isso pode influenciar diretamente no sucesso ou no fracasso em sua caminhada para a aprendizagem e para sua atuação profissional.
\end{abstract}

Palavras-chave: Emoções. Língua estrangeira. Língua inglesa. Feedback corretivo oral. Teoria sociocultural.

\begin{abstract}
In this article we present an analysis of emotions in a classroom teaching setting as well the relation that can be established between the oral corrective feedback and emotions, by data triangulation and how it can enhance the future teacher formation and the language teaching and learning. The article also tries to identify learners reaction to the oral corrective feedback given by the teacher or by their peer in the english classroom setting. The results show that learners present different feelings regarding the corrective feedback and this can be directly related to their beliefs. These results can also have an effect on the success or failure of learners` learning and professional development.
\end{abstract}

Keywords: Emotions. Foreign language. English language. Oral corrective feedback. Sociocultural theory. 
Os efeitos das emoções no ensino-aprendizagem de inglês...

\section{Introdução}

Diversos autores (ARNOLD, 1999; ARNOLD; BROWN, 1999; BARCELOS, 2013; BARCELOS; COELHO, 2010; OXFORD, 2003; MASTRELLA, 2005) argumentam que as emoções exercem um papel central no desenvolvimento e no funcionamento psicológico humano, visto que para compreender tal processo precisamos levar em consideração não só o aspecto cognitivo, mas também os sentimentos vivenciados pelos envolvidos no ensino-aprendizagem de línguas. Nesse sentido, acreditamos que ensinar e aprender uma nova língua envolve uma complexidade de fatores que não podem ser isolados em si mesmos, pois todos estão imbricados e atuam de diversas maneiras em diferentes sujeitos, grupos e contextos.

Ao considerarmos esses pressupostos e tomarmos as proposições da pesquisa interpretativista, abordamos, neste artigo, os fatores afetivos que podem influenciar na formação do futuro professor de línguas com base no processo de correção oral e o ensinoaprendizagem de inglês, assim como algumas crenças de aprendizes e da professora a respeito desses processos para que se possa refletir sobre tais questões.

Para tanto, inicialmente discutimos as noções conceituais de emoções que sustentam a pesquisa, vinculando-as à concepção sociocultural e ao feedback corretivo oral. Após, explicitamos a forma de coleta dos dados; apresentamos e discutimos os dados coletados com os futuros professores de inglês e com a professora, verificando o reflexo dessas ações na futura prática docente e no ensinoaprendizagem de línguas.

\section{Fatores afetivos e o ensino de línguas}

A interação social é a base para o desenvolvimento de um indivíduo, pois permite a intersubjetividade (interações sociais e simbólicas) entre os envolvidos na aprendizagem por meio de processos cognitivos e afetivos que sustentam a ação humana.

Assim, ao buscar uma abordagem abrangente, capaz de compreender o sujeito em sua totalidade, Vygotsky une os aspectos 
afetivos e o cognitivo de modo dialético e nos mostra que cada ideia contém uma atitude afetiva que exerce uma influência recíproca ao longo da história do desenvolvimento e do funcionamento psicológico humano, não sendo possível dissociar o lado afetivo do cognitivo (intelectual).

Vygotsky (1987) acreditava que uma das grandes fraquezas da psicologia tradicional era justamente a separação do afeto da cognição, pois, para ele, as emoções são derivadas do contato social e cultural do indivíduo com o meio e medeiam a aprendizagem juntamente com a cognição. De acordo com ele, "o pensamento possui suas origens na esfera motivacional da consciência, um âmbito que integra nossas inclinações e necessidades, nossos interesses e impulsos, nossos afetos e emoções. A tendência afetiva e volitiva fica atrás do pensamento", (VYGOTSKY, 1987, p. 282).

Dessa maneira, podemos dizer que o afeto engloba as emoções e os sentimentos que podem mediar o comportamento, o pensamento e os objetivos de um indivíduo (IMAI, 2010), e a cognição diz respeito ao conhecimento e ao pensamento de cada um (SWAIN; KINNEAR; STEINMAN, 2011).

Por serem intensas e possuírem uma carga cognitiva que sustenta a ação humana, as emoções podem mediar o desenvolvimento do ser humano, dado que elas aparecem primeiramente no plano social e somente depois são internalizadas no plano psicológico (SWAIN; KINNEAR; STEINMAN, 2011; SWAIN, 2011) a partir do contato que estabelecemos com os outros.

Assim como Arnold e Brown (1999), concordamos que a atenção às emoções e aos fatores afetivos pode levar a uma aprendizagem mais significativa, uma vez que o aspecto afetivo e o cognitivo da aprendizagem caminham lado a lado (ARNOLD; BROWN, 1999). A união da emoção e da cognição nos faz compreender melhor as trajetórias de aprendizagem de línguas, tendo em vista que as emoções não podem ser ignoradas nesse processo (SWAIN, 2011).

\footnotetext{
1 "Thought has its origins in the motivating sphere of consciousness, a sphere that includes our inclinations and needs, our interests and impulses, and our affect and emotions. The affective and volitional tendency stands behind thought" (VYGOTSKY, 1987, p. 282).
} 
No campo do ensino-aprendizagem de L2 ou LE, as emoções são vistas como um termo guarda-chuva e têm sido compreendidas como afeto: aspectos da emoção, sentimentos, humor, atitudes e crenças que condicionam o comportamento e influenciam no ensinoaprendizagem de línguas (ARAG ̃̃O, 2011).

Assim, abordamos, na sequência, os fatores afetivos considerados para a coleta e a análise dos dados que se relacionam diretamente ao ensino-aprendizagem de línguas e ao processo corretivo como um todo, a saber: ansiedade, autoestima, motivação e crenças.

\subsection{Ansiedade}

Tem sido dito que a aprendizagem de uma LE em sala de aula suscita ansiedade em muitos aprendizes por requerer uma participação expositiva maior em um contexto de avaliação constante (HORWITZ et al., 1991). Ao adquirir uma nova língua, o aprendiz é exposto a algumas situações conflitantes, pois mesmo sem possuir uma competência linguística na língua-alvo ele procura expressar as experiências na língua que está aprendendo de alguma forma. Ao se expor, o aluno estará sujeito a receber um feedback do professor, uma vez que a avaliação está relacionada ao desempenho do aprendiz. Essa atmosfera pode trazer sentimentos de apreensão, desconforto, tensão, entre outros, que estão associados à ansiedade e muitas vezes são apontados como obstáculos ao ensino-aprendizagem de línguas.

Logo, podemos definir ansiedade como o medo ou a apreensão que toma conta do aprendiz quando ele é solicitado ou precisa produzir algo na LE (OXFORD, 1999). Alguns alunos, por exemplo, ficam ansiosos por medo de errar, de receber uma correção negativa perante os pares ou de se expor em sala de aula diante do professor e dos colegas.

Consequentemente, a ansiedade pode fazer com que os alunos fiquem nervosos, frustrados e tensos, o que contribui para um desempenho insatisfatório na língua, por mais que eles saibam muito sobre ela (MASTRELLA, 2005; ARNOLD; BROWN, 1999). Para Horwitz (2001), a ansiedade possui uma relação estreita com o desempenho dos alunos nas tarefas em sala de aula, causando e sendo também reforçada pelo baixo rendimento no desenvolvimento da proficiência na língua-alvo. 
Para Tsui (1995), a ansiedade pode ser diminuída por meio do estabelecimento de uma boa relação entre os envolvidos no processo de ensino-aprendizagem, da redução da competitividade presente em sala de aula, da interação mediada entre os aprendizes e do estímulo ao relaxamento dos aprendizes com a utilização de atividades mais lúdicas (músicas, jogos, filmes) em sala de aula.

\subsection{Autoestima}

Os indivíduos formam sua autoestima por intermédio de suas experiências sociais, individuais, culturais e também pelas avaliações do mundo ao seu redor (BROWN, 1994a). Por meio dela, a pessoa pode achar que é capaz ou não de realizar alguma atividade ou produzir algo na LE. Um aspecto considerável na literatura da autoestima é que ela é passível de aumento ou de diminuição consoante as conquistas da pessoa em áreas que lhe são importantes. Assim como a ansiedade, a autoestima pode ser um traço da personalidade do indivíduo ou um estado relacionado a uma situação específica vivida pela pessoa em um determinado momento de sua vida (SCARCELLA; OXFORD, 1992).

Na sala de aula de LE, os aprendizes que possuem autoestima mais elevada com relação à sua capacidade de aprendizagem da língua têm maior probabilidade de obter mais sucesso do que aqueles que não acreditam em sua capacidade porque não estão preocupados em errar e não se intimidam com as possíveis críticas e correções advindas do professor e/ou dos colegas.

Em contrapartida, o excesso de correção pode levar à baixa autoestima e bloquear o processo de aprendizagem da LE (ANDRÉS, 1999), podendo estar ligada ao receio do aprendiz em parecer estúpido ao cometer erros. A baixa autoestima pode levar os aprendizes a acreditar que as situações são mais complicadas do que elas são na realidade, uma crença que, conforme Pajares (1996), provoca tensão e uma visão limitada quanto à melhor maneira de resolver uma dificuldade e de agir em sala de aula.

Segundo Andrés (2001), o melhor modo de desenvolver a autoestima em sala de aula de LE é conduzir os alunos a realizações concretas, fazendo-os reconhecê-las e apreciá-las. Destacamos também que o professor deveria sempre lembrar-se de que não está ensinando 
Os efeitos das emoções no ensino-aprendizagem de inglês...

uma legião, mas pessoas individuais, com necessidades e anseios específicos.

\subsection{Motivação}

A motivação é um dos termos bastante recorrentes em estudos que pretendem explicar o sucesso ou o possível fracasso dos alunos no ensino-aprendizagem de línguas e se relaciona aos desejos ou impulsos internos relativos a um objetivo (BROWN, 1994a), podendo ser originada por fatores internos e externos, tais como a prática de ensino, o material didático, a interação entre os pares e o ambiente institucional. A compreensão da motivação requer um entendimento do indivíduo como um ser humano inserido em um contexto social no qual interage, modificando-o e sendo modificado por ele.

De acordo com Arnold e Brown (1999), um dos estudos significativos sobre o papel da motivação na aprendizagem de línguas é o de Gardner e Lambert (1972), no qual eles dividem a motivação em dois tipos de orientação: a integrativa e a instrumental (DORNEY; RYAN, 2015). Na orientação integrativa, a motivação está fundamentada nos aspectos da personalidade do indivíduo e favorece a proficiência na LE. Há também um interesse do aprendiz de se integrar à comunidade falante nesse tipo de motivação. Na orientação instrumental, por sua vez, a motivação está associada aos benefícios práticos que o aluno pode vir a ter ao aprender a língua-alvo, como a habilidade de se comunicar e a capacidade de ler textos escritos na língua que está sendo aprendida, o sucesso profissional, entre outros.

Com relação à aprendizagem, os comentários positivos e construtivos do professor podem levar o aprendiz a ficar mais motivado e a explorar novas áreas de conhecimento (TSUI, 1995). No entanto, ao receber correções ambíguas ou uma avaliação negativa do professor, o aluno pode ficar confuso e se sentir desmotivado a querer produzir ou a participar das aulas de maneira mais ativa.

Nesse sentido, concordamos com Tsui (1995) quando afirma que um professor que valoriza as contribuições e fornece um feedback encorajador provavelmente irá motivar mais o aluno a aprender e a participar nas aulas, além de criar um ambiente social agradável na sala de aula. $\mathrm{O}$ auxílio entre pares também pode ser um motivador para 
alunos tímidos, inseguros ou até mesmo para aqueles que demonstram pouco interesse nas aulas (OXFORD, 1999).

Quando corrigimos os erros orais, sempre temos uma preocupação com os efeitos positivos e/ou negativos que a correção pode ter nos alunos. Dessa forma, Tsui (1996) sugere que o professor forneça um tempo razoável para que o aluno possa pensar sobre a pergunta que lhe foi feita em sala de aula. A pesquisadora (TSUI, 1996) também chama a atenção dos professores para que não percebam o silêncio do aluno, ao refletir sobre a melhor forma de responder aos questionamentos do professor, como um fator negativo, uma vez que ele permite o bom relacionamento entre o professor e o aluno.

Com o intuito de investigar o papel e o significado das emoções no processo de aprendizagem de uma L2, Imai (2010) pesquisou como os aprendizes manifestaram suas emoções na comunicação verbal em L2 ao longo de um semestre. O autor descreveu como um grupo de aprendizes de inglês construiu e compartilhou suas atitudes emocionais em uma tarefa em grupo e como a intersubjetividade emocional os levou à co-construção do conhecimento. Com a análise interpretativa dos dados coletados, Imai (2010) concluiu que as emoções medeiam o desenvolvimento, especialmente quando a aprendizagem está relacionada à troca de conhecimentos entre os envolvidos no processo.

\subsection{Crenças}

As crenças podem ser definidas como um construto dinâmico, variável, estando baseadas na experiência de cada pessoa, pois resultam da interação social e estão em constante mudança (BARCELOS, 2000; VYGOTSKY, 1978). Nesse sentido, elas são definidas como dinâmicas, emergentes, socialmente construídas e situadas contextualmente, experienciais, mediadas, paradoxais, contraditórias, relacionadas à ação de uma maneira indireta e complexa (KALAJA; BARCELOS, 2003).

Barcelos (2004) destaca que as crenças são um conceito social porque nascem de nossas experiências com o meio e de nossa capacidade de refletir sobre aquilo que nos cerca. Woods (2003) afirma ainda que as crenças são estruturadas e interconectadas, não são entidades estáveis em um indivíduo, mas estão situadas em contextos 
sociais e são formadas por meio da interação social e, como resultado, evoluem constantemente.

Com relação ao ensino-aprendizagem de línguas, as crenças caracterizam-se como

uma forma de pensamento, como construções da realidade, maneiras de ver e perceber o mundo e seus fenômenos, coconstruídas em nossas experiências e resultantes de um processo interativo de interpretação e (re) significação. Como tal, crenças são sociais (mas também individuais), dinâmicas, contextuais e paradoxais (BARCELOS, 2006, p. 18).

Quando estudamos as crenças e o ensino-aprendizagem de LE, podemos encontrar algumas generalizações, visto que as crenças são uma forma de pensamento e são construídas por meio da interação do indivíduo com o meio com base em sua experiência e história de vida pessoal e social. Dewey (1933) já afirmava que as crenças contemplam todas as matérias sobre as quais não temos conhecimento pleno, mas em que confiamos o bastante para poder nelas basear nossas ações.

Autores como Barcelos (2001; 2006), Pajares (1992), VieiraAbrahão (2004) e outros sugerem que a importância do estudo das crenças reside no fato de que elas influenciam direta ou indiretamente a ação das pessoas. Em se tratando de sala de aula de LE, as crenças do professor podem influenciar em sua prática de ensino, na maneira como ele realiza a correção, tornando-a mais eficaz, podendo também as crenças dos alunos intervir no sucesso ou não da aprendizagem como um todo (ZHENG, 2009). De acordo com Kalaja (1995), as crenças podem mudar de um aluno para outro, de um contexto para outro e até mesmo dentro de um mesmo contexto.

As crenças dos professores e dos alunos apresentam aspectos cognitivos e sociais (BARCELOS, 2000, 2008; WOODS, 2003), o que faz com que cada indivíduo seja único e, ao mesmo tempo, pertencente a sistemas sociais distintos. Essas características evidenciam que as crenças estão sempre em movimento, podendo influenciar e sofrer influências, evoluir e transformar-se com base nas relações sociais situadas em um determinado contexto. Pajares (1992) acredita que as crenças se formam cedo na vida das pessoas. Para o autor, elas vão se 
refinando em razão de outras fontes, tais como: a docência, as práticas estabelecidas pelas instituições em que os professores atuam, a própria personalidade do professor, as pesquisas, as abordagens e os métodos utilizados pelo professor.

Silva e Figueiredo (2006) salientam que a concepção sobre o erro está, muitas vezes, relacionada ao modo de agir das pessoas em suas vidas cotidianas, uma vez que elas possuem suas próprias definições e crenças sobre o erro e o ensino-aprendizagem de línguas, algumas delas já estabelecidas e outras em processo de maturação, podendo ser modificadas ou não.

\section{Metodologia da investigação}

Para compreender as questões expostas anteriormente, investigamos de forma qualitativa e interpretativista a realidade social do contexto específico com base na construção e na atribuição conjunta de significados dos sujeitos, com a análise do processo interativo e reflexivo dos dados (CRESWELL, 2010).

$\mathrm{O}$ estudo foi realizado em uma turma de nível $\mathrm{V}$ do curso de Letras/Inglês e respectivas Literaturas de uma universidade privada do Estado do Rio Grande do Sul. A escolha do contexto deve-se ao fato de a turma estar em um nível pré-intermediário a intermediário de inglês e por ser um local de formação de professores, em que os participantes puderam refletir sobre a correção como alunos e também como futuros professores. A seleção intencional dos participantes auxilia o pesquisador a entender melhor o problema e a questão de pesquisa, determinando o palco para a discussão das questões que estão envolvidas na coleta de dados.

Os alunos (dez alunos, sendo sete mulheres e três homens) e a professora participaram das seguintes etapas da pesquisa: narrativa escrita, gravação em áudio e vídeo das aulas, entrevista semiestruturada oral e sessão de visionamento (gravada em áudio e transcrita). Além disso, foram utilizados como instrumentos de coleta de dados as notas de campo e a observação em sala de aula pela pesquisadora.

Primeiramente, os participantes escreveram um texto narrativo a respeito de sua experiência como aprendizes de LE, como 
começaram a estudar, qual foi a motivação, etc. Justifica-se o uso das narrativas por ser um meio de se obter informações a respeito das experiências anteriores de aprendizagem dos professores e dos alunos (PAVLENKO; LANTOLF, 2000).

A entrevista semiestruturada teve como finalidade obter informações acerca das concepções dos aprendizes sobre a correção oral, sentimentos, relação com o idioma, etc. A entrevista com a professora teve como objetivo coletar informações a respeito de suas percepções sobre o processo de correção oral.

A gravação em áudio e vídeo ocorreu ao longo de 13 aulas, tendo sido gravadas e transcritas 15 horas da interação oral em sala de aula, tempo disponibilizado pela professora e que não corresponde ao total das horas observadas pela pesquisadora. Por sua vez, as sessões de visionamento foram realizadas após as gravações das aulas, pois os alunos puderam refletir e tecer comentários individuais a respeito de suas atitudes e interações em sala de aula a partir do contato direto com suas gravações.

Por fim, os alunos escreveram novamente um texto narrativo como um meio para compreender e organizar nosso entendimento sobre o mundo, o que permitiu que os alunos refletissem sobre seu desempenho ao longo do semestre. Os dados foram coletados durante aproximadamente um semestre - três meses e duas semanas de um total de quatro meses - de aulas da referida turma.

Neste artigo serão enfatizados os fatores afetivos relacionados ao feedback corretivo oral no processo de interação entre os envolvidos no ensino-aprendizagem de inglês com base na triangulação dos dados coletados.

\section{Resultados}

Os aprendizes relataram tanto nas entrevistas semiestruturadas como nas sessões de visionamento ter sentimentos positivos e/ou negativos quanto à correção oral fornecida pela professora e/ou colega que remetem à vergonha e ao constrangimento ao serem expostos ao erro e ao sentimento positivo ao receberem a correção oral.

Por meio da triangulação dos dados, percebemos que os aprendizes defendem o uso de correções que não afetem de forma 
negativa sua autoestima. Por essa razão, a maioria dos alunos prefere interações em grupos e técnicas que não os estimule a participar das interações perante a turma, para que, assim, não sejam expostos. É por isso também que alunas mais extrovertidas, como Paula e Rafaela, acabam participando mais das interações em sala de aula do que os outros colegas.

Paula:

Eu acho que é benéfica, mas tem um jeito de corrigir o aluno sem constranger ele. Não pode dizer a ele que ele está errando o tempo todo. Tem muitos alunos e colegas que têm uma trava na fala porque eles têm medo de participar e de errar, se sentem constrangidos e tímidos na hora de participar. Então, do meu ponto de vista é assim: se você tem uma forma de chegar até o aluno e corrigir o erro sem mostrar a ele que ele está sendo corrigido, melhor. Agora, se você não tem uma forma para fazer isso, é melhor não corrigir. Tem um jeitinho. Às vezes é melhor deixar que o aluno, por conta, vá notando. Pelo menos ele não vai ter um bloqueio.

(Dados da entrevista semiestruturada com os aprendizes)

Paula acredita nos benefícios da correção, levando em consideração o feedback afetivo que a correção proporciona a seus colegas e a outros aprendizes. Na opinião dos participantes, a melhor forma de correção é aquela que cria um ambiente saudável em sala de aula, e a menos eficiente é aquela que expõe o aluno ao erro, deixandoo constrangido, como é ilustrado nos seguintes exemplos.

Mara:

Eu acredito que sim, mas tem que ter uma forma de como você vai corrigir o aluno ou qualquer outra pessoa. Se você expor ele ao ridículo, eu acho que ele vai ter um trauma, talvez essa seja a maior dificuldade dos alunos. Às vezes a gente tem vergonha ou passou por uma experiência humilhante de correção, e isso faz com que a gente não queira mais falar. Mas eu acho que é válido. Aqui na 
faculdade com certeza é necessário. Eu preciso falar certo para poder ensinar o certo para meus alunos.

Juliano:

Se a correção for de um jeito que não constranja o aluno, eu concordo que ela seja feita. Agora, se for num tom que iniba o aluno, eu já não acho muito legal não. Aquela coisa, você pode aproveitar o exemplo e depois trabalhar com o erro num outro momento.

\section{Lucas:}

Desde que feita de uma maneira tranquila e saudável, tem que se corrigir. Tudo tem o seu momento. Às vezes você está trabalhando e percebe que o aluno tá errando, e aquele não é o momento para a correção. Acho que é totalmente fundamental.

(Dados da sessão de visionamento com os aprendizes)

O aspecto afetivo e os efeitos que a correção têm na autoestima dos aprendizes é algo bastante recorrente em suas falas. Eles influenciam na maneira como os aprendizes aprendem a língua com base nas interações que eles estabelecem com outros indivíduos (SWAIN, 2011).

Nesse sentido, os sentimentos positivos apresentados pelos aprendizes estão atrelados ao fato de os colegas possuírem uma boa relação por estarem estudando juntos desde o primeiro semestre, pela segurança da professora, a autoestima, pela visão da correção como uma prática comum em sala de aula e a motivação de aprender a língua para o futuro profissional. Os aprendizes ainda consideram a correção como parte do processo de ensino-aprendizagem da LE.

Com relação aos sentimentos negativos, os aprendizes destacam que ter seus erros expostos perante a turma toda e ao possível julgamento dos colegas e da professora levou alguns deles a se sentirem envergonhados ou constrangidos na interação oral, o que fez com que sua participação em sala de aula na coleta de dados fosse 
reduzida a fim de evitar o erro, o feedback corretivo da professora e uma exposição adiante da turma.

Outra questão importante a se destacar é a timidez, a insegurança com relação à língua e a personalidade introvertida de alguns aprendizes. Esses fatores contribuem para um tipo de ansiedade classificada por Oxford (1999) como ansiedade relativa, pois se caracteriza justamente pelo desconforto causado por uma atividade na qual se exige que o aluno participe oralmente.

Os fatores citados acabam influenciando na proficiência e na motivação dos aprendizes com relação à LE. Consideremos esses fatores nos excertos seguintes:

Mara:

Eu fico vermelha porque eu morro de vergonha de tudo, mas eu acredito que eu vou aprender e tentar acertar da próxima vez que eu for falar a palavra que a professora corrigiu.

Duda:

Quando a correção é feita de forma que eu sinto que é para melhorar, fico grata, mas quando o professor expõe o erro para todos eu me sinto envergonhada.

Oscar:

Eu gosto quando me corrigem porque eu aprendo quando os professores me corrigem. Dependendo do jeito que o professor corrige na frente dos colegas, eu me sinto muito envergonhado.

Alice:

$\mathrm{Na}$ verdade, todos os professores têm seu jeitinho de corrigir. Eu prefiro escrever do que falar, porque às vezes fico um pouco constrangida da professora estar me avaliando. Eu entrei na faculdade para aprender, então é melhor que eu aprenda o erro aqui na faculdade do que lá fora ensinando, mesmo que eu me sinta constrangida.

Lucas: 
Eu me sinto um pouco constrangido, mas isso eu acho que é uma questão de ordem pessoal, mas só que isso eu não levo muito em conta. Depende de como o professor te corrige.

(Dados da entrevista semiestruturada com os aprendizes)

As falas de Duda, Alice e Oscar mostram que eles se preocupam com o julgamento que os outros colegas e até mesmo a professora possam fazer acerca de suas produções. Notamos que cada aluno possui sua necessidade particular e tem expectativas distintas com relação à correção oral da professora (ou dos colegas). Os alunos também defendem uma correção que não afete de forma negativa sua autoestima, recaindo a crença de não expor negativamente o aluno. Brown (1994b) reitera que o sucesso que os aprendizes obtêm em uma tarefa resulta, em parte, das crenças que eles têm sobre sua capacidade de realizar a tarefa, o que é corroborado pela professora Bel na sua resposta a uma das questões da entrevista com relação às crenças dos aprendizes.

\section{Professora Bel:}

Certamente. Eu percebo assim que eles só se transformam naquilo que eles acreditam, nas possibilidades de transformação deles, mesmo a gente falando para eles tentar falar, se arriscar, que não há problema em errar. Enquanto que o aluno não toma consciência dessa atitude como necessária à qualificação da aprendizagem dele, ele também não faz, por mais que a gente insista. Então é um processo de amadurecimento enquanto aprendiz de língua estrangeira e também da própria superação dos medos, das vergonhas, das inseguranças, que depende de cada um. Alguns conseguem fazer isso e outros não.

De modo geral, podemos perceber pela fala dos alunos e também da professora que as diferenças individuais dos aprendizes influenciam na maneira como eles agem em sala de aula e que as emoções não podem ser desprezadas no entendimento do processo de ensino-aprendizagem de línguas (SWAIN, 2011). Os relatos dos 
aprendizes alertam sobre o cuidado que devemos ter ao corrigir os alunos, pois se a correção não for feita como uma forma de suporte ela poderá configurar-se como um meio de exposição aos erros, causando inibição, ansiedade e frustração aos aprendizes. Concordamos com Swain (2011) quando ela afirma que a união da cognição e da emoção nos auxilia a compreender as trajetórias de ensino-aprendizagem da LE.

Com relação às crenças dos aprendizes, podemos inferir que todos eles (dez participantes) consideram a correção importante para o processo de ensino-aprendizagem de uma língua, ainda que apresentem sentimentos positivos e negativos quanto ao feedback corretivo oral. Além disso, eles mencionaram que gostariam que seus erros fossem corrigidos sempre, porém de uma maneira adequada (que não constranja ou exponha o aprendiz perante os colegas) pela professora, pois o bom relacionamento entre o professor e os alunos é fundamental para que haja uma atmosfera positiva para a aprendizagem (TSUI, 1996). Observamos, assim, que a maioria dos alunos do estudo confia na professora como a responsável pela correção.

Os sentimentos representados com base nos dados correspondem às experiências vivenciadas pelos aprendizes por meio das emoções e às crenças (BARCELOS, 2006) que cada um carrega consigo. Eles podem tanto facilitar como inibir o desenvolvimento na língua-alvo dos aprendizes, dependendo da situação de ensinoaprendizagem vivenciada por eles em sala de aula. Quando os aprendizes se deparam com uma situação que os faz se sentir desconfortáveis, por exemplo, eles podem desistir de participar da interação, e isso pode bloquear as tentativas de comunicação desses aprendizes (BROWN, 1994a). Alguns aprendizes acreditam ainda que não conseguem expressar-se na língua-alvo, o que acaba por inibir sua capacidade comunicativa (BURDEN, 2005).

\section{Considerações finais}

Neste artigo buscamos analisar os fatores afetivos presentes na interação em torno do feedback corretivo oral recebido pelos aprendizes. Com base nesta análise pudemos fazer algumas inferências relacionadas às experiências dos aprendizes no processo de ensino- 
aprendizagem de línguas. Com este trabalho percebemos também que os fatores afetivos, positivos e negativos, ou seja, aqueles que fazem o aluno progredir na língua ou que ainda limitam seu desempenho, podem levar os alunos a ter sucesso ou fracasso em sua caminhada para a aprendizagem da língua e para a futura docência.

Como resultado desta pesquisa, evidenciamos que os alunos apresentam duas reações com relação ao feedback corretivo oral fornecido pela professora. Alguns aprendizes se sentem bem com a forma de correção fornecida pela professora, apresentando sentimentos positivos em relação à correção, ao passo que outros ficam tímidos ou constrangidos com a correção recebida, o que pode prejudicar sua autoestima e a relação com a aprendizagem da língua-alvo como um todo no momento da interação social. Os fatores afetivos, incluindo as crenças, são influenciados pelo meio linguístico e por valores socioeducacionais de cada um (SATO, 2013).

Concordamos com Oxford (1999) e Swain (2011) quanto aos benefícios dessa relação bidirecional entre o fator afetivo e o cognitivo, pois a atenção aos aspectos afetivos pode melhorar o ensinoaprendizagem de línguas e educar os aprendizes afetivamente. Assim, não devemos ignorar o lado afetivo (emocional) quando corrigimos os aprendizes, "unindo mente e coração na sala de aula" (ARNOLD; BROWN, 1999, p. 3).

Desse modo, é fundamental que consideremos o ponto de vista de Swain (2011), que salienta o valor das emoções em sala de aula, afirmando que precisamos refletir sobre o que está mediando as respostas emocionais dos professores aos alunos, dos alunos aos professores e dos alunos às atividades que lhes proporcionamos.

Finalmente, acreditamos que futuras pesquisas precisariam compreender melhor a recorrência das emoções não só na correção oral, bem como na escrita, em especial pelo alcance linguístico que ela encerra como formadora de professores de línguas.

2 "Bringing together mind and heart in the classroom" (ARNOLD; BROWN, 1999, p. 3). 


\section{Referências}

ANDRÉS, Verónica. Self-esteem in the classroom or the metamorphosis of butterflies. In: ARNOLD, Jane. (Ed.). Affect in language learning. Cambridge: Cambridge University Press, 1999. p. 87-102.

. Writing from the heart - writing for the soul - encouraging children to wake up the writer within. Humanistic Language Teaching, year 3, n. 1, short article, 2001. Disponível em: <http://www.hltmag.co.uk>. Acesso em 15 jul. 2015.

ARAGÃO, Rodrigo. Beliefs and emotions in foreign language learning. System, v. 39, p. 303-313, 2011.

ARNOLD, Jane; BROWN, Harold D. A map of the terrain. In: ARNOLD, Jane. (Ed.). Affect in language learning. Cambridge: Cambridge University Press, 1999. p. 1-24.

BARCELOS, Ana Maria F. We teach who we are. Perspectives, v. 10, p. 2-6, 2013.

. Understanding teachers' and students' anguage learning beliefs in experience: A Deweyan Approach. Tese (Doutorado em Ensino de Inglês como Segunda Língua) - The University of Alabama, Tuscaloosa, AL, USA, 2000.

- Metodologia de pesquisa das crenças sobre aprendizagem de línguas: estado da arte. Revista Brasileira de Linguística Aplicada, v. 1, n. 1, p. 71-92, 2001.

- Crenças sobre aprendizagem de línguas, Linguística Aplicada e ensino de línguas. Linguagem e Ensino, Pelotas, v. 7, n. 1, p. 101-121, 2004.

- Narrativas, crenças e experiências de aprender inglês. Linguagem e Ensino, v. 9, n. 2, p. 145-175, 2006. 
Os efeitos das emoções no ensino-aprendizagem de inglês...

. Finding my own voice and accent. Humanizing Language Teaching. v. 10, n. 3, 2008. Disponível em: <http://www.hltmag.co.uk/jun08/sart03.htm>. Acesso em 29 jun. 2015.

BARCELOS, Ana Maria F. COELHO, Hilda S. (Org.) Emoções, reflexões e (trans)form(ações) de alunos, professores e formadores de professores de línguas. Campinas: Pontes Editores, 2010.

BROWN, Harold D. Principles of language learning and teaching. New Jersey: Prentice Hall, 1994a.

Teaching by principles: an interactive approach to language pedagogy. New Jersey: Prentice-Hall, 1994b.

BURDEN, Peter. The teacher as a facilitator: reducing anxiety in the EFL university classroom. Jalt Hokkaido Journal, v. 8, p. 3-18, 2005.

CRESSWELL, John W. Projeto de pesquisa: métodos qualitativo, quantitativo e misto. São Paulo: Bookman, 2010.

DEWEY, John. How we think. Lexington: D. C. Health and Company, 1933.

DORNEY, Zoltán; RYAN, Stephen. The psychology of the language learner revisited. New York: Routledge, 2015.

GARDNER, Robert. C.; LAMBERT, Wallace. E. Attitudes and motivation on second language learning. Rowley, MA: Newbury House, 1972.

HORWITZ, Elaine K. Language anxiety and achievement. Annual Review of Applied Linguistics, v. 21, p. 112-126, 2001.

HORWITZ, Elaine K.; HORWITZ, Marie B.; COPE, Jo. A. Foreign language classroom anxiety. In: HORWITZ, Elaine K.; YOUNG, Dolly J. Language anxiety: from theory and research to classroom implications. Englewood Cliffs, NJ: Prentice Hall, 1991. p. 27-36. 
IMAI, Yasuhiro. Emotions in SLA: New insights from collaborative learning for an EFL classroom. The Modern Language Journal, v. 94, n. 2, p. 278-292, 2010.

KALAJA, Paula. Students beliefs (or metacognitive knowledge) about language SLA reconsidered. International Journal of Applied Linguistics, v. 5, n. 2, p. 191-204, 1995.

KALAJA, Paula. Research on students' beliefs about SALA within a discursive approach. In: KALAJA, Paula; BARCELOS, Ana Maria F. (Org.). Beliefs about SLA: New research approaches. Kluwer Academic Publishers. Netherlands, 2003. p. 87-108.

MASTRELLA, Mariana R. Ansiedade e crenças: considerações sobre a afetividade em sala de aula de língua inglesa. In: MELLO, Heloísa A. B.; DALACORTE, Maria C. F. (Org.). A sala de aula de língua estrangeira. 2. ed. Goiânia: Ed. da UFG, 2005. p. 115-153.

OXFORD, Rebecca L. Anxiety and the language learner: new insights. In: ARNOLD, Jane. (Ed.). Affect in language learning. Cambridge: Cambridge University Press, 1999. p. 58-67.

PAJARES, Frank M. Teacher's beliefs and educational research: cleaning up a messy construct. Review of Educational Research, v. 62, n. 3, p. 307-332, 1992.

Self-efficacy in academic settings. Review of Educational Research, v. 4, p. 543-578, 1996.

PAVLENKO, Aneta; LANTOLF, James P. Second language learning as participation and the(re)construction of selves. In: LANTOLF, James P. (Ed.). Sociocultural theory and second language learning. New York: Oxford University Press, 2000. p. 155-177.

SATO, Masatoshi. Beliefs about peer interaction and peer corrective feedback: efficacy of classroom intervention. The Modern Language Journal, v. 97, n. 3, p. 611-626, 2013. 
Os efeitos das emoções no ensino-aprendizagem de inglês...

SCARCELLA, Robin C.; OXFORD, Rebecca L. The tapestry of language learning: The individual in the communicative classroom. Boston: Heinle \& Heinle Publishers, 1992.

SILVA, Sulene V.; FIGUEIREDO, Francisco J. Q. Erro e correção: as crenças de dois professores de escola pública e de alguns de seus alunos. Revista Brasileira de Linguística Aplicada, v. 6, n. 2, p. 113$141,2006$.

TSUI, Amy B. M. Introducing classroom interaction. London: Penguin English, 1995.

. Reticence and anxiety in second language learning. In: BAILEY, Kathleen M.; NUNAN, David. (Ed.). Voices from the language classroom: quantitative research in second language acquisition. Cambridge: Cambridge University Press, 1996. p. 145167.

VIEIRA-ABRAHÃO, Maria. Helena. Crenças, pressupostos e conhecimentos de alunos-professores de língua estrangeira e sua formação inicial. In: VIEIRA-ABRAHÃO, Maria Helena. (Org.). Prática de ensino de língua estrangeira: experiências e reflexões. Campinas: Pontes, 2004. p. 131-152.

SWAIN, Merrill. The inseparability of cognition and emotion in second language learning. Language Teaching, v. 46, n. 2, p. 195-207, 2011.

SWAIN, Merrill; KINNEAR, Penny; STEINMAN, Linda. Sociocultural theory in second language education: an introduction through narratives. New York: MM Textbooks, 2011.

VYGOTSKY. Lev. S. Mind in society: the development of higher psychological processes. Cambridge: Havard University Press, 1978.

. Thinking and speech. In: RIEBER, Robert W.; CARTON, Aaron S. (Ed.). The collected works of L.S. Vygotsky, Volume 1: 
problems of general psychology, including the volume. New York: Plenum Press, 1987. p. 39-285.

WOODS, Devon. The social construction of beliefs in the language classroom. In: KALAJA, Paula; BARCELOS, Ana. Maria F. New approaches to research on beliefs about SLA. Amsterdã: Kluwer, 2003. p. 55-86.

ZHENG, Hongying. A review of research on EFL pre-service teachers' beliefs and practices. Journal of Cambridge Studies, v. 4, n. 1, p. 1-9, 2009.

Submetido em: 15/09/2015 Aceito em: 11/10/2015

Title: The effects of emotions on the learning and teaching of English and on language teacher education: an analysis from the oral corrective feedback 